\title{
Narrativas de Práticas Pedagógicas de Professoras que Ensinam Matemática na Educação Infantil
}

\section{Pedagogical Practices Narratives of Teachers who teach Mathematics in Childhood Education}

Priscila Domingues de Azevedo*

\begin{abstract}
Resumo
Este artigo identifica a produção, o reconhecimento e a ressignificação de conhecimentos metodológicos e matemáticos que se revelaram nas narrativas orais e escritas de professoras da Educação Infantil, quando reunidas em um grupo de estudo colaborativo sobre a Educação Matemática na infância. Trata-se de uma pesquisa de cunho qualitativo que, pela análise de conteúdo, evidenciou indícios de desenvolvimento profissional manifestados pelas participantes do grupo em processo de formação continuada. Identificaram-se, a partir das narrativas, as abordagens metodológicas redimensionadas pelas professoras no processo de formação no grupo; os conhecimentos matemáticos possíveis de trabalhar a partir de jogos; e os aspectos da aprendizagem colaborativa que ocorreu no grupo. Em síntese, destaca-se que as narrativas reflexivas produzidas pelas professoras se revelaram como um elemento de reflexão e formação docente, pois puderam tomar mais consciência de sua própria prática, refletir, avaliar e aprimorar seu trabalho pedagógico.
\end{abstract}

Palavras-chave: Narrativas de Professoras. Educação Matemática na Infância. Formação Continuada de Professores. Grupo Colaborativo.

\begin{abstract}
This article identifies the production, recognition and redefinition of methodological knowledge and mathematicians shown in oral and written narratives of teachers in Childhood Education, when they gather in a group collaborative study on mathematics education in childhood. This is a qualitative research which, through content analysis, showed evidence of professional development manifested by the group participants in the process of continuing education. Methodological approaches resized by teachers in the process of forming the group, mathematical knowledge possible to work from the games, and aspects of collaborative learning that occurred in the group were identified from the narratives. In summary, it is emphasized that the produced narratives became an element of reflection and continuous education, because they could be more aware of their own practice, reflect, evaluate, and improve their pedagogical work.
\end{abstract}

\footnotetext{
* Doutora em Educação pela Universidade Federal de São Carlos (UFSCar), São Carlos, São Paulo, Brasil. Mestre em Educação pela Universidade Estadual Paulista (UNESP), Presidente Prudente, São Paulo, Brasil. Pedagoga pela Universidade Estadual Paulista (UNESP), Marília, São Paulo, Brasil. Estagiária pós-doutoral na Universidade Federal de São Carlos (UFSCar), São Carlos, São Paulo, Brasil. Endereço para correspondência: Avenida Carmem Aparecida Garcia, 137, Parque Fehr, CEP: 13.563-776, São Carlos, SP, Brasil. E-mail: priscila_azevedo_7@hotmail.com.
} 
Keywords: Narratives of Teachers. Mathematical Education in Childhood. Continuous Education of Teachers. Collaborative Group.

\section{Introdução}

Este artigo procura enfatizar o percurso de aprendizagens desencadeadas a partir do “Grupo de Estudos Outros Olhares para a Matemática” - GEOOM - e identificar a produção, o reconhecimento e a ressignificação dos conhecimentos matemáticos e metodológicos que se revelaram nas narrativas orais e escritas de professoras da Educação Infantil participantes do grupo.

A experiência do GEOOM, desde 2010, destaca a importância de práticas formativas no processo de formação continuada e permanente de professores, pois elas possibilitaram o desenvolvimento profissional dos envolvidos, que puderam aprofundar concepções e conhecimentos matemáticos e metodológicos. Diante dessa experiência, as professoras tornaram-se sujeitos protagonistas de sua profissão e adquiriram autonomia para produzir inovações curriculares.

A partir das discussões das aprendizagens da profissão docente ao longo da vida, neste artigo utilizamos as narrativas orais e escritas como elemento potencializador de reflexão e de desenvolvimento profissional de professores em processo de formação continuada.

Trabalhar com as narrativas na pesquisa é buscar um olhar mais detalhado e atento às experiências do professor. É possível estabelecer, entre a narrativa e a experiência, uma relação dialética que requer

parar para pensar, parar para olhar, parar para escutar, pensar mais devagar, olhar
mais devagar, e escutar mais devagar; parar para sentir, sentir mais devagar,
demorar-se nos detalhes, suspender a vontade, suspender o automatismo da ação,
cultivar a atenção e a delicadeza, abrir os olhos e ouvidos, falar sobre o que nos
acontece, aprender a lentidão, escutar aos outros, cultivar a arte do encontro, calar
muito, ter paciência e dar-se tempo e espaço. (LARROSA, 2002, p. 24).

O uso de narrativas faladas e escritas por professores nos permitem ouvir sua voz; eles são atores e autores de sua própria história, que pode ser ouvida e compartilhada. Entendemos que as narrativas "provocam mudanças na forma como as professoras compreendem a si próprias e aos outros e, por esse motivo, são, também, importantes estratégias formadoras de consciência numa perspectiva emancipatória" (CUNHA, 1997, p. 01).

Além disso, Passos (2009, p. 114) afirma que o exercício de escrita contribui significativamente na formação dos professores, pois os faz pensar sobre os desafios que 
enfrentam no cotidiano de suas práticas. A reflexão e a (re)significação compõem o que "seria um processo pelo qual produzimos (novos) significados e (novas) interpretações sobre o que sabemos, dizemos e fazemos".

Também Souza (2010, p. 17) enfatiza a importância da narrativa: ao narrar, "o sujeito toma consciência de si e de suas aprendizagens experienciais quando vive, simultaneamente, os papéis de ator e de investigador da sua própria história”. As narrativas utilizadas como prática de formação trazem aproximações das memórias e das trajetórias dos professores com seus percursos e aprendizagens da docência, podendo envolver projetos de formação e autoformação para os docentes.

Tomando Gauthier e colaboradores (1998) como referência, podemos dizer que, ao produzir as narrativas escritas, as professoras participantes desta pesquisa tornaram públicos seus saberes que, em primeira instância, eram pessoais e particulares, e, com isso, contribuíram para um debate com seus pares.

Também a partir das narrativas orais, os professores podem partilhar suas próprias experiências com seus pares, ocorrendo o que Nacarato (2008) denomina de "validação de saberes”. Esses saberes são (com)partilhados, refletidos e/ou rejeitados e, de certo modo, apropriados pelos pares, que incorporam novos saberes.

Freitas e Fiorentini (2007, p. 66) complementam essas considerações: afirmam que o professor, ao relatar oralmente suas experiências aos outros, aprende e ensina. "Aprende, porque, ao narrar, organiza suas ideias, sistematiza suas experiências e produz novos aprendizados. Ensina porque o outro, frente às narrativas de experiências do colega, pode (re)significar seus próprios saberes e experiências".

Desse modo, as narrativas escritas e orais, e até alguns desenhos, podem desencadear um processo de organização da experiência a ser narrada, o que promove a reflexão e a metacognição (FERREIRA, 2003; FREITAS; FIORENTINI, 2007; NACARATO; LOPES, 2009). As narrativas, ainda segundo Freitas e Fiorentini (2007), são um modo de refletir, relatar e representar a experiência; produzem sentido ao que somos, fazemos, pensamos, sentimos e dizemos.

\section{Metodologia}

Este artigo é um recorte da pesquisa de doutorado de Azevedo (2012), desenvolvida numa abordagem qualitativa, a fim de valorizar os dados qualitativos (descrição detalhada de 
situações, pessoas, interações, comportamentos, falas, atitudes, concepções, pensamentos e trechos de narrativas) como importantes e preciosos para assegurar o compromisso com a produção de conhecimento (LÜDKE; ANDRÉ, 1986).

Em Educação Matemática, a pesquisa qualitativa é notável: nas suas inúmeras variantes, ela "dá atenção às pessoas e às suas ideias, procura fazer sentido de discursos e narrativas que estariam silenciosas" (D’AMBROSIO, 2004, p. 21).

Os dados da pesquisa foram coletados no período de março de 2010 a julho de 2012 e construídos a partir de narrativas reflexivas (orais e escritas) produzidas pelas professoras. Esses textos foram utilizados como um elemento de coleta de dados, e muitos deles serviram como estratégias no processo de formação das professoras participantes do grupo, pois se revelaram potencializadores de reflexão e de desenvolvimento profissional de professores em processo de formação continuada.

As narrativas escritas eram uma das tarefas das professoras do grupo: ao final de cada semestre escreviam um texto em forma de narrativa. No entanto, a entrega era bem flexível, de acordo com as condições de cada autora.

As narrativas orais foram captadas em gravação de vídeo nos encontros do grupo GEOOM. Assistidos e interpretados os vídeos pela pesquisadora, esta reconheceu, com base em Powell, Francisco e Maher (2004), que esse instrumento, aliado a outros, nos dá elementos importantes para a configuração da pesquisa.

Todos os vídeos foram gravados por uma bolsista do projeto de extensão da UFSCar, instituição à qual o grupo está vinculado. Orientada pela pesquisadora para realizar as gravações, a bolsista estudou o texto de Powell e colaboradores (2004) e a temática sobre Educação Matemática na infância e entendeu a questão da pesquisa e seus objetivos. Mesmo assim, reconhecemos que houve fragilidades nesse processo, pois sempre há, segundo Powell e colaboradores (2004), o olhar da pessoa que está filmando que, implícita ou explicitamente, edita e escolhe exemplos quando focaliza, pois não consegue filmar tudo. Depois do momento da gravação, o papel da pesquisadora foi observar atentamente os dados do vídeo; descrevêlos; identificar falas importantes; transcrevê-las; codificar; construir enredo; e compor as narrativas das participantes.

A análise esteve presente em vários estágios da pesquisa, o que a tornou mais sistemática e formal após o encerramento da coleta de dados. Primeiramente, foi feita uma pré-análise, seguida da exploração do material obtido e do tratamento dos resultados, da inferência e da interpretação. Segundo Bardin (2011), a pré-análise é a fase de organização 
propriamente dita. Assim, primeiramente, escolhemos os documentos que seriam submetidos à análise - filmagens, produção de textos reflexivos e narrativas que obtivemos -; a partir disso, formulamos hipóteses e as relacionamos com nosso problema de pesquisa e com os objetivos; e então, elaboramos indicadores que fundamentaram a interpretação final, segundo o referencial teórico adotado.

Foram selecionados trechos das narrativas orais e escritas das professoras, como unidades de significação (BARDIN, 2011), visando categorizar os dados a partir dos aspectos encontrados. Os dados apresentados neste artigo indicam as observações pontuais das abordagens metodológicas redimensionadas pelas professoras no processo de formação no grupo e os conhecimentos matemáticos possíveis de trabalhar a partir de jogos e histórias infantis. Essas categorias estabelecidas a posteriori emergiram da fala e do discurso das professoras, o que implicou constantes idas e voltas - do material de análise à teoria.

\section{As narrativas de práticas pedagógicas de professoras que ensinam Matemática na Educação Infantil}

Foram produzidas narrativas orais e escritas sobre diversas temáticas estudadas no GEOOM, como: jogos de boliche, tiro ao alvo, amarelinha, quebra-cabeça, dominó e caixas que contam histórias. As professoras também narraram situações problemas que envolveram os sólidos geométricos e o trabalho com medida.

Essas narrativas evidenciaram as abordagens metodológicas redimensionadas pelas professoras do grupo que, pela aprendizagem colaborativa, deram indícios de desenvolvimento profissional e da socialização do conhecimento produzido.

Sempre foi enfatizado, no grupo, que as narrativas escritas são únicas e não seriam lidas para receber nota de 0 a 10. Ademais, a formadora-pesquisadora não corrigiu erros de língua portuguesa, a não ser nos textos que seriam publicados em eventos ou os que serão publicados em livro, em fase de organização. Pelo contrário, os relatos que cada professora escreveu sempre foram valorizados e comentados no grupo. No geral, era a autora quem relatava oralmente, no grupo, o que havia escrito.

Ao longo de três anos e meio (de 2010 a 2013), 41 professoras participaram do grupo, no qual se reuniram e conviveram - em momentos e em espaços de tempo nem sempre coincidentes. Isto é, o grupo começou com 10 professoras, depois algumas saíram e outras entraram, em um movimento contínuo. Durante esse período, as narrativas evoluíram e o 
exercício da escrita ficou mais familiar às professoras, que revelaram constantemente que o lúdico passou a fazer parte da sua própria prática e não somente dos textos lidos no grupo. Destacaremos neste artigo algumas narrativas referentes ao jogo de boliche e ao tiro ao alvo.

Um dos primeiros temas escolhidos pelo grupo para estudo foi o jogo de boliche. A partir dessa escolha, a formadora-pesquisadora indicou a leitura e o estudo de três textos: um de Moura (1996), intitulado "Jogo de boliche"; outro de Almeida (2008), "E eu que não acreditava"; e outro de Costa (2008), "Oba, hoje é dia de boliche”. A leitura dos dois últimos textos em forma de narrativa animou e incentivou as professoras do GEOOM a implementar esse jogo em suas turmas e a escrever sobre a experiência realizada. Esse foi um aspecto importante, visto que a leitura ajudou a mobilizar as professoras em duas perspectivas: colocar em ação o que estavam aprendendo e socializar com o grupo os resultados.

O trabalho com o jogo de boliche ressaltou aspectos importantes do processo do brincar e do ensinar e aprender Matemática na Educação Infantil.

As discussões no grupo GEOOM evidenciaram a importância de levar a criança a levantar hipóteses sobre o jogo, sobre suas regras e organização. Os conhecimentos prévios das crianças começaram a nortear o planejamento e o trabalho das professoras. Depois do levantamento desses conhecimentos, as professoras discutiram com seus alunos as diferentes organizações do jogo de boliche.

A professora Antônia ${ }^{1}$, que tinha uma turma com crianças de 5 e 6 anos, narrou com riqueza de detalhes, utilizando as falas das crianças para mostrar suas hipóteses sobre o jogo:

Iniciamos no dia 20 de abril, durante a roda de conversa, uma discussão sobre o que sabiam a respeito do jogo de boliche - Eles já sabiam que íamos fazer um jogo, pois logo que pedi para trazerem as garrafas, já questionaram o motivo.

$\mathrm{O} \mathrm{Ka}$ começou falando que tinha que pegar a bola, jogar e derrubar (a fala das crianças é muito interessante, pois falam como se estivéssemos dentro de seu pensamento, vendo o que eles vêm, e o mais interessante é que todas as crianças parecem compreender!). Então questionei: “derrubar o quê??". E o Ma completou que eram os pinos. Perguntei o que faria as vezes de pinos para nós, e todos responderam que eram as garrafas; todas as crianças já conheciam o jogo. (Antônia, 26 abr. 2010)

Narrativas como esta ajudaram o grupo a entender que dar a oportunidade de as crianças construírem o jogo, manipularem as peças, organizarem o espaço e experimentarem regras e organizações, possibilitou que elas pudessem, pela experiência, chegar a algumas

\footnotetext{
1 Todos os nomes mencionados são fictícios e escolhidos pelas próprias professoras participantes do grupo GEOOM.

${ }^{2}$ Os nomes das crianças, escritos e/ou falados pelas professoras, foram substituídos pelas iniciais dos nomes deles, para preservar suas identidades.
} 
conclusões sobre o jogo e mostrou como as questões metodológicas envolvem diretamente as questões conceituais da Matemática.

Segundo Moura (1996), ao estabelecer relações entre a disposição espacial das garrafas e a possibilidade de derrubar o maior número delas, a criança aprende a planejar suas jogadas.

Além de dar oportunidade de as crianças jogarem, construírem e adaptarem regras, é importante que o trabalho com o jogo tenha uma regularidade para a criança ir se apropriando, aos poucos, dos conceitos que envolvem o jogo.

Depois de terem jogado por algum tempo, o trabalho com gráficos, tabelas, representações pictóricas, orais e escritas auxiliou as crianças no seu processo de aprendizagem de contagem; comparação de quantidades; noção do zero - toda vez que não derrubavam garrafas; ideias de adição e subtração; noção espacial; e registro pictórico, numérico e gráfico.

Grando (2004, p. 59) afirma: "é importante que o professor procure estabelecer estratégias de intervenção que gerem a necessidade do registro escrito do jogo, a fim de que não seja apenas uma exigência, sem sentido para a situação de jogo".

A professora Maria Clara, que trabalhou com um cartaz para a marcação dos pontos, o qual as crianças utilizavam para o registro, fez a seguinte narrativa escrita sobre esse momento:

[...] Nesta rodada, cada aluno que jogava registrava os pontos numa tabela, cujos pontos eram marcados com um pino feito de E.V.A. em um cartaz confeccionado com papel cartão, foto de cada criança e velcro.

No final perguntei quem tinha feito mais pontos e não compreenderam. Diante disso, pedi para que pegassem palitos de sorvete de acordo com os pontos marcados. Dessa maneira, puderam compreender melhor a noção de quantidade. Nesse momento, ia comparando quantidades de palitos entre os alunos.

Atividade riquíssima, para ser trabalhada com crianças menores, no ensino da matemática, pois, através do lúdico, as crianças aprendem os conhecimentos matemáticos.

Vale ressaltar que houve muito entusiasmo e até torcida durante o jogo e diariamente eles falavam: "Tia, vamos brincar de boliche hoje?” (Maria Clara, 26 abr. 2010).

O excerto da narrativa da professora Maria Clara mostra que não foi rápido nem simples o processo de as crianças contarem os pontos que fizeram no boliche e isso não é um problema de aprendizagem, mas faz parte do processo de construção do conceito de número. Segundo Van de Walle (2009), o número envolve muitas ideias, relações e habilidades diferentes e é necessário tempo, além de muitas experiências, para que as crianças desenvolvam uma compreensão completa do número. 
Além do registro no cartaz, algumas professoras solicitaram às crianças um registro pictórico e, com a experiência, perceberam a importância de socializar os desenhos entre as crianças, para explorar seus detalhes. Por exemplo, nos desenhos dos jogos representaram a organização do espaço, as regras do jogo, os jogadores e outras coisas que estavam em cena.

Segundo Lopes (2009) e Smole (2003), a representação pictórica é uma das linguagens da criança, considerada sua primeira escrita. É uma forma de expressão do pensamento, mas nem sempre o adulto a compreende, por isso é importante conversar com a criança sobre o desenho.

As docentes reconheceram que, a partir do desenho da criança, poderiam ter um olhar mais afinado para avaliar não apenas a forma como ela percebeu o jogo, mas também sua própria prática docente. Os desenhos, então, tornaram-se uma forma de feedback do processo de ensino e aprendizagem e passaram a interferir na prática pedagógica do professor.

No entanto, até então, as professoras não tinham o costume de solicitar que as crianças desenhassem o jogo, não socializavam os desenhos produzidos e não davam a elas oportunidade de refazer o desenho. A partir do estudo no grupo, algumas delas propuseram o registro pictórico às crianças, mas ainda não haviam pedido para desenharem novamente o mesmo jogo. Isso era algo que o grupo precisava discutir mais.

Os registros foram realizados com as crianças depois que estas já tinham jogado algumas vezes: as tabelas foram feitas durante o jogo, com a marcação dos pontos; e o gráfico e a representação pictórica, depois do jogo. Segundo Grando (2004), o momento do registro depende da natureza do jogo trabalhado e dos objetivos que se estabelecem.

Além dos registros, foi também importante o trabalho com a contagem no jogo de boliche: as crianças queriam saber quantos pinos tinham derrubado e, ao final do jogo, juntaram as quantidades obtidas em cada jogada, para saberem quanto conseguiram no jogo. A escrita da representação numérica foi, muitas vezes, auxiliada pelas professoras, o que é absolutamente natural nesse processo, pois as crianças aprendem a grafar os algarismos, que têm uma relação arbitrária com as representações das quantidades.

As professoras puderam perceber que as crianças são capazes de jogar, entender o jogo, conversar sobre ele e registrar coletivamente ou individualmente aspectos que fazem parte dele, como a contagem e o controle de quantidades.

A literatura (GRANDO, 2004; KISHIMOTO, 1994, 1996, 1998; MOURA, 1996) afirma que os jogos podem auxiliar a ação docente, pois, a partir deles, pode se desenvolver conceitos, noções e habilidades de diversas áreas do conhecimento, entre elas a Matemática, e 
esta pesquisa vem reforçar ainda mais essa ideia. As professoras perceberam, em especial, que o jogo de boliche é algo muito significativo para a criança, pois permite trabalhar gradualmente as noções matemáticas.

Algum tempo após as discussões sobre o boliche, a professora Bianca elaborou com as crianças de quatro e cinco anos de sua turma um jogo de tiro ao alvo chamado "Pontos coloridos", que foi apresentado no grupo como uma das alternativas para trabalhar o controle de quantidades e as relações espaciais em uma atividade lúdica. Bianca levou ao grupo o jogo que ela havia construído, explicou as regras para as colegas, mostrou como jogar e detalhou oralmente e depois por escrito o trabalho que desenvolveu:

Numa busca sobre materiais recicláveis na internet, me deparei com um objeto feito com sete garrafas pets unidas com fita adesiva e decorado com durex colorido.

Apresentei às crianças e perguntei a elas o que poderíamos fazer com aquele objeto. Dentre várias sugestões, a de que mais gostamos foi de fazer um jogo. Perguntei-lhes como seria, e uma das crianças sugeriu que tentássemos acertar dentro das garrafas com alguma coisa. Usamos para isso potinhos ovais que tínhamos na sala. Também fizemos marcações no chão para definir o lugar das garrafas e do jogador.

Após algumas jogadas, sugeri que fossem atribuídos pontos diferentes para cada cor. Reproduzi a figura na lousa e perguntei-lhes como deveria ser a pontuação. Um garotinho disse que o verde deveria valer mais porque era mais difícil de acertar. E outra criança sugeriu que fosse cinco. Disseram, então, que o vermelho deveria valer 4, e o azul 3, o amarelo valeria 2 porque estava mais perto e era mais fácil de acertar. Não quiseram atribuir o valor 1, pois este seria muito pouco.

Definida a pontuação, começamos novamente a jogar. Surgiu, então, a necessidade de marcar esses pontos. Sugeri que eles usassem tampinhas de garrafa para isso. Cada criança que acertasse em uma das garrafas deveria pegar a quantidade de tampinhas correspondentes aos pontos definidos pela cor. Fizemos o jogo algumas vezes coletivamente e deixei-o à disposição das crianças na sala.

Percebi uma melhora significativa na contagem, pois algumas crianças não a dominavam ainda, o reconhecimento do numeral e a relação número-quantidade também ficaram mais clara para eles.

No jogo fazia sentido contar, para saber quantos pontos a criança fez, para saber quem fez mais pontos depois de algumas jogadas e definir o ganhador.

Além disso, esse jogo proporcionou uma percepção do espaço, favorecendo também o desenvolvimento da noção do espaço que estava envolvido nesta atividade/brincadeira, para melhor explorá-lo e conseguir fazer boas jogadas.

Depois de algumas semanas, quando retomamos o jogo de forma coletiva, envolvendo a turma toda, surgiu a necessidade de darmos um nome para o jogo. Após algumas sugestões das crianças, fizemos uma votação e ficou definido que o jogo se chamaria "Pontos coloridos".

Ao retomá-lo de forma coletiva, dividi a turma em dois grupos e fizemos um minicampeonato de cinco dias, nos quais anotávamos, ao final de cada partida, quantos pontos cada criança fez, e depois somávamos/contávamos os pontos de cada grupo. Ao final dos cinco dias, somamos/contamos os pontos de cada grupo, definindo o grupo ganhador do campeonato, bem como somamos os pontos individuais e conhecemos o melhor jogador de "Pontos coloridos" da turma. A premiação foi feita 
com medalhas de papel dourado para o grupo vencedor e uma especial (em tamanho maior) para o melhor jogador.

Como todos os outros jogos e brincadeiras que fizemos neste ano, o "Pontos coloridos" foi usado como uma estratégia de ensino da Matemática, mas esse jogo, em particular, acredito que foi muito significativo para essa turma, pois, ao participarem da criação desse jogo, tiveram que resolver diversas situações problemas colocadas pela própria situação de criação além do jogar, favorecendo, assim, o desenvolvimento do raciocínio lógico-matemático. (Bianca, $04 \mathrm{dez}, 2011)$

O relato escrito da professora Bianca nos traz diversos elementos para pensar mais uma vez sobre o trabalho com o conhecimento matemático por meio dos jogos. Uma característica importante é que ela foi elaborando as regras do jogo coletivamente com a turma. A atitude da professora de perguntar para as crianças o que poderiam fazer com o material foi interessante, pois ela ouviu as crianças, conversou com elas e definiram coletivamente que iriam fazer um jogo.

No grupo, discutimos que, no geral, a ansiedade das professoras não as deixa conversar com as crianças e definir coletivamente um jogo: já chegam apresentando o jogo e definindo as regras. Dar voz à criança e incentivar a imaginação, a criatividade e a autonomia é papel das professoras da Educação Infantil. Assim, quando a professora Bianca colocou o desafio para as crianças criarem o jogo, ela acreditou na capacidade delas de criar, deu-lhes oportunidade de exercer seu protagonismo. Para Faria (2005) e Horn (2004, 2005), o protagonismo infantil é essencial para que as crianças criem e desenvolvam sua autonomia.

$\mathrm{Na}$ atividade descrita pela professora Bianca, elencar a pontuação do jogo foi possível, pois as crianças experimentaram antes o material e perceberam qual garrafa seria a mais fácil de acertar e qual seria a mais difícil. As crianças atribuíram sentido à pontuação, compararam os números e definiram uma relação entre posição e valor. Essa atitude das crianças de elaborar coletivamente as regras do jogo possibilitou que elas pensassem mais sobre ele. Segundo Kamii e DeVries (2009), essa prática é de alto valor educacional, pois as crianças têm que pensar para fazer um bom jogo. Elas utilizam o raciocínio espacial para organizá-lo. Além disso, ao decidirem suas regras, exercitam o pensamento e a linguagem.

Durante o jogo, para marcar os pontos, a turma da professora Bianca usou tampinhas de garrafa, um bom recurso para contagem e para estabelecer a relação biunívoca.

Outro aspecto positivo pode ser aqui apontado: as crianças desenvolveram a noção e a percepção espacial, tomaram consciência do espaço e do próprio corpo, o que lhes possibilitou boas jogadas. Segundo Kamii e DeVries (2009, p. 72), os jogos de "alvo" favorecem a estruturação do espaço, “já que as crianças refletem sobre relações espaciais 
quando miram um objeto em direção a um alvo específico". Esses jogos, segundo as autoras, exigem abstração reflexiva, além de coordenação perceptivo-motora. Apoiadas nos estudos de Piaget, essas pesquisadoras afirmam serem os esquemas lógico-aritmético e espaçotemporal criados pela abstração reflexiva, que possibilita à criança perceber todos os atributos que envolvem os objetos, como a cor, o peso e o material de que são feitos; ela consegue estabelecer relações entre eles, como "o mesmo", "diferente”, “dois", além de outras.

É relevante também destacar, na narrativa da professora Bianca, que, depois de a turma jogar um determinado tempo, surgiu a necessidade de dar um nome ao jogo. Fizeram, então, uma votação e definiram: "Pontos coloridos". Dar um nome ao jogo possibilitou às crianças mais uma relação de identificação com ele, uma relação de proximidade: ele passou a fazer parte do cotidiano do grupo de crianças, tornou-se especial, pois foram construindo o jogo e suas regras.

Outro aspecto importante utilizado pela professora foi a votação. Segundo Kamii (1990), a função mais importante da votação é colocar o poder de decisão nas mãos das crianças, promovendo, dessa forma, sua autonomia. Além disso, para conferir os votos, foi necessária uma contagem, um registro que exige a comparação de quantidades. Essa prática de votar não é tão fácil na Educação Infantil, pois muitas crianças votam mais de uma vez. Ela precisa ser aprendida e, nesse momento, o papel do professor é fundamental: ele pode conferir o número de crianças votantes e depois, ao somar o total de votos, verificar se há a mesma quantidade de crianças. Para a criança aprender a votar, ela precisa ter várias oportunidades de exercitar isso; assim, a cada oportunidade, ela pode ser lembrada de que poderá votar somente uma vez, de que só pode fazer uma escolha.

Por fim, a professora Bianca montou um minicampeonato com as crianças. A competição no jogo, segundo Grando (2000), garante o dinamismo, o movimento, propicia interesse e envolvimento espontâneo das crianças, contribui para seu desenvolvimento social, intelectual e afetivo. As crianças ficaram muito motivadas, somavam os pontos, torcendo para ganhar a medalha de papel dourado feita pela professora. $\mathrm{O}$ interessante é que esta reconheceu o esforço do grupo que conseguiu mais pontos e também da criança com pontuação maior e considerou pontos individuais e coletivos. Isso fez com que cada criança desse o melhor de si.

Ao narrar esse episódio no grupo de estudo, a professora disse que as crianças dos dois grupos se ajudavam nas jogadas, esclarecendo regras e apontando estratégias para acertar a garrafa que valia mais. Com isso, a competição ficou minimizada, e o objetivo tornou-se a socialização do conhecimento do jogo, compondo, afinal, uma competição sadia. 
Ao final da narrativa, a professora destaca que as crianças tiveram que resolver diversas situações problemas colocadas pela própria criação do jogo, além do ato de jogar propriamente dito. É interessante observar que a professora compreende a resolução de problema em uma perspectiva metodológica, ou seja, ela concebe ensinar por meio da resolução de problemas e propôs problemas de diferentes naturezas. A resolução de problemas apontada pela professora é um aspecto importante no jogo, pois traz vantagens ao processo de criação e construção de conceitos. Segundo Grando (2000, p. 32),

\begin{abstract}
o jogo propicia o desenvolvimento de estratégias de resolução de problemas na medida em que possibilita a investigação, ou seja, a exploração do conceito através da estrutura matemática subjacente ao jogo e que pode ser vivenciada, pelo aluno, quando ele joga, elaborando estratégias e testando-as a fim de vencer o jogo. $\mathrm{O}$ cerne da resolução de problemas está no processo de criação de estratégias e na análise, processada pelo sujeito, das várias possibilidades de resolução. No jogo ocorre fato semelhante. Ele representa uma situação problema determinada por regras, em que o indivíduo busca a todo o momento, elaborando estratégias e reestruturando-as, vencer o jogo, ou seja, resolver o problema. Esse dinamismo característico do jogo é o que possibilita identificá-lo no contexto da resolução de problemas.
\end{abstract}

Dessa forma, o dinamismo do jogo "Pontos coloridos" fez com que as crianças da turma da professora Bianca se motivassem a resolver problemas desde o momento da escolha dos números que ficariam em cada uma das cores das garrafas. Eles haviam testado o jogo antes de as garrafas estarem numeradas, elaboraram estratégias para conseguir acertar o alvo e, quando propuseram os números, puderam testar se as estratégias favoreciam a vitória, ou seja, se obteriam a maior quantidade de pontos. Além de demonstrarem a construção de conhecimento lógico-matemático na escolha dos números para cada cor, eles desenvolveram a habilidade de contar, de somar e também lidaram com abstração reflexiva, estabelecendo relações espaço-temporais, pois o jogo fez sentido para elas.

A narrativa da professora Bianca revela que, ao deixar o jogo à disposição das crianças na sala, ele passou a fazer parte de momentos da brincadeira livre, quando algumas crianças se reuniram para jogar e deixou de ocorrer apenas em um momento dirigido, com a turma toda. Segundo Barbosa (2006), é fundamental que a criança tenha momentos coletivos e momentos diversificados, com jogos e brincadeiras coletivas e individuais. A autora também revela que, quando o professor deixa à disposição das crianças um amplo repertório de materiais, elas têm a possibilidade de ampliar a variedade de atividades da rotina. Isso dá a elas maior autonomia e os adultos se veem menos esgotados, o que facilita o estabelecimento de relações serenas e equilibradas.

Ao compartilhar sua experiência com as demais professoras, Bianca pôde expressar que as crianças gostaram de jogar várias vezes, de modo dirigido ou sozinhas, e que essa 
rotina é importante no processo de aprendizagem. Conforme explicita Barbosa (2006), ao repetir uma ação, a criança aprende um jeito diferente de fazer algo que sabe, qualificando habilidades que estão sendo desenvolvidas. Repete-se um jogo para aprender a fazê-lo; é na repetição que se constroem e consolidam determinadas estruturas mentais - portanto, é fundamental dar tempo para as crianças repetirem jogos e brincadeiras, seja de modo dirigido, livre, coletivo ou individual.

As atividades com jogos, relatadas pelas professoras Antônia, Maria Clara e Bianca, vêm comprovar a afirmação de Moura (1996) de que o jogo é um importante recurso pedagógico, que proporciona à criança a construção do seu próprio conhecimento matemático e a compreensão das regras que regem a produção coletiva desse conhecimento. Ao jogar, a criança adquire novo saber sobre si mesma, sobre os papéis sociais, sobre as regras da vida em grupo, sobre os conceitos básicos das diversas áreas do conhecimento construído pelo homem ao longo da história.

\section{0 processo de significação do conhecimento das professoras}

Diante dos dados expostos e de indícios de aprendizagem profissional revelados nas narrativas orais e escritas apresentadas, constatamos que muitas professoras passaram por um processo de mudança: construíram ou ressignificaram conhecimentos. Assim, como na pesquisa de Grando e Nacarato (2007), as discussões e as produções escritas tornaram os conhecimentos tácitos das professoras mais visíveis. No coletivo do grupo, as docentes levantaram questões e suposições sobre práticas comuns que possibilitaram novas ações na prática docente.

Durante os vários encontros do grupo, fomos percebendo que as professoras tinham interesse em conhecer o trabalho desenvolvido pela colega; começavam a valorizar, quando uma colega estava narrando uma experiência; passaram a dar valor à experiência do outro e ajudá-lo a pensar como resolver seus problemas e suas dificuldades, surgidos no trabalho docente.

As professoras, durante sua participação no grupo, aprenderam a ouvir e a falar a respeito de sua prática docente. Nos primeiros encontros, quando uma delas falava, as demais não davam muita atenção ou importância. Contudo, depois de terem sido orientadas pela formadora-pesquisadora, começaram a perceber que tudo é importante e, assim, passaram a prestar mais atenção ao que as colegas diziam. 
As práticas descritas pelas professoras são de uma determinada realidade, um tempo e um espaço, mas podem proporcionar um exercício de reflexão para outros professores, dando a eles a oportunidade de construir suas próprias práticas pedagógicas, por isso, não haverá receitas de boas práticas nas narrativas produzidas pelas professoras participantes do GEOOM, mas ideias que podem ser apropriadas e/ou adaptadas, visto que a Educação Infantil é um campo complexo e, ao mesmo tempo, rico em possibilidades.

\section{Considerações finais}

As professoras perceberam que o jogo é algo muito significativo para a criança, pois permite trabalhar gradualmente as noções matemáticas. Os conhecimentos matemáticos nem sempre estavam explícitos nas narrativas orais e escritas das professoras e estas nem sempre narravam qual conceito matemático foi aprendido ou ressignificado, mas indícios foram aparecendo, à medida que as professoras reportavam a forma como conduziram seu trabalho pedagógico com as crianças.

Os jogos de boliche e tiro ao alvo, explicitados neste artigo, entusiasmaram as professoras, mas foi papel da formadora-pesquisadora colaborar com o grupo e destacar que as situações lúdicas poderiam apresentar conceitos matemáticos que poderiam ser trabalhados de forma integrada, dando aos jogos possibilidades múltiplas de aprendizagem matemática.

Portanto, no grupo foi trabalhada a intencionalidade das professoras, para que pudessem definir quais conhecimentos matemáticos iriam ser priorizados no trabalho com jogo. Percebemos que o professor não tem condições de planejar intervenções pedagógicas a partir do jogo e agir de modo intencional, se ele próprio não reconhecer os conhecimentos matemáticos que são utilizados nas atividades propostas.

Tais conhecimentos foram discutidos coletivamente, no grupo; desse modo, a formadora não chegava com o conceito pronto, mas todos juntos iam discutindo, até chegar à meta estabelecida, que era compreender um conceito presente nos jogos. A comunicação e a negociação foram fundamentais no grupo, mas não nos esquecíamos de que era preciso chegar a uma definição, pois a Matemática não pode ser interpretativa.

A pesquisa de Azevedo (2012) mostrou que nem sempre o professor tem consciência de todos os conceitos matemáticos envolvidos nos jogos. As professoras participantes do GEOOM só os reconheceram quando os estudaram teoricamente, partilharam suas dúvidas, dividiram experiências e refletiram sobre sua própria prática. Dessa forma, esses recursos 
materiais serviram como ferramenta de apoio para o grupo desenvolver ideias coletivamente e aprender colaborativamente. A matemática estava na problematização que fazíamos a partir do material didático pedagógico.

As narrativas orais e escritas das professoras revelaram que nem sempre estas apresentavam um conhecimento formal da Matemática, mas conseguiam processualmente, com os estudos no grupo, perceber as relações matemáticas intuitivas que as crianças faziam.

As professoras reconheceram que o boliche e o tiro ao alvo, entre outros materiais pedagógicos, e o jogo, por si sós, não ensinam Matemática, pois é necessário que o professor e a criança estabeleçam uma relação com o material, para que o conhecimento matemático possa ser produzido.

Percebemos que a produção, o reconhecimento e a ressignificação dos conhecimentos matemáticos, a partir dos aspectos conceituais desencadeados pela aprendizagem colaborativa e relacionados aos conhecimentos matemáticos e metodológicos, redimensionados pelas professoras, se revelaram nas narrativas orais e escritas.

A pesquisa mostrou que conhecimentos matemáticos e metodológicos podem ser produzidos e ressignificados por uma formação continuada em um grupo de estudo colaborativo, e as narrativas orais e escritas podem servir como elemento de reflexão e formação docente.

Os resultados do trabalho revelam a utilização de práticas formativas em um grupo com características colaborativas que teve um domínio comum de interesse e de trabalho. Esse modo de fazer formação continuada deu às participantes oportunidade de aprofundar concepções e conhecimentos matemáticos e tornar-se sujeitos protagonistas de sua profissão, pois adquiriram mais autonomia para realizar suas práticas pedagógicas.

O processo de aprender coletivamente num grupo pode ter influência na prática pedagógica do professor, que, por sua vez, pode sentir-se motivado a (com)partilhar suas experiências com seus pares, a ponto de avaliar sua prática, trocar ideias e aprimorar e/ou promover mudanças em seu trabalho. 


\section{Referências}

ALMEIDA, R. E eu não acreditava... In: GRANDO, R. C.; TORICELLI, L.; NACARATO, A. M. (Org.). De professora para professora: conversas sobre iniciaAção matemática. São Carlos: Pedro \& João Editores, 2008. p. 25-30.

AZEVEDO, P. D. O conhecimento matemático na Educação Infantil: o movimento de um grupo de professoras em processo de formação continuada. 2012. 245f. Tese (Doutorado em Educação) Universidade Federal de São Carlos, São Carlos, 2012.

BARBOSA, M. C. S. Por amor e por força: rotinas na educação infantil. Porto Alegre: Artmed, 2006.

BARDIN, L. Análise de conteúdo. São Paulo: Edições 70, 2011.

COSTA, I. A. B. Oba, hoje é dia de boliche. In: GRANDO, R. C.; TORICELLI, L.; NACARATO, A. M. (Org.). De professora para professora: conversas sobre iniciação matemática. São Carlos: Pedro \& João Editores, 2008. p. 31-36.

CUNHA, M. I. Conta-me agora! As narrativas como alternativas pedagógicas na pesquisa e no ensino. Revista da Faculdade de Educação, São Paulo, v. 23, n. 1-2, jan./dez. 1997. Disponível em: $<$ http://www.scielo.br/scielo.php?pid=S0102-25551997000100010\&script=sci_arttext $>$. Acesso em: 13 ago. 2012.

D’AMBROSIO, U. Prefácio. In: BORBA, M. C.; ARAÚJO, J. Loiola (Org.). Pesquisa qualitativa em Educação Matemática. Belo Horizonte: Autêntica, 2004. p. 11-23.

FARIA, A. L. G. Políticas de regulação, pesquisa e pedagogia na educação infantil, primeira etapa da educação básica. Educação e Sociedade, v. 26, n. 92, Especial, p. 1.013-1.038, out. 2005. Disponível em: 〈http://www.scielo.br/pdf/es/v26n92/v26n92a14.pdf>. Acesso em: 20 jun. 2012.

FERREIRA, A. C. Metacognição e desenvolvimento profissional de professores de matemática: uma experiência de trabalho colaborativo. 2003. 368 f. Tese (Doutorado em Educação) - Faculdade de Educação, Universidade Estadual de Campinas, Campinas, 2003.

FREITAS, M. T. M.; FIORENTINI, D. As possibilidades formativas e investigativas da narrativa em educação matemática. Horizontes, Itatiba, SP, v. 25, n. 1, p. 63-71, jan./jun. 2007.

GAUTHIER, C. et al. Por uma teoria da pedagogia: pesquisas contemporâneas sobre o saber docente. Ijuí: Ed. Unijuí, 1998. (Coleção Fronteiras da Educação).

GRANDO, R. C. O conhecimento matemático e o uso de jogos na sala de aula. Tese (Doutorado em Educação) - Faculdade de Educação, Universidade Estadual de Campinas, Campinas/SP, 2000.

GRANDO, R. C. O jogo e a matemática no contexto da sala de aula. São Paulo: Paulus, 2004.

GRANDO, R. C.; NACARATO, A. M. Educadoras da infância pesquisando e refletindo sobre a própria prática em matemática. Revista Educar - UFPR, Curitiba, n. 30, p. 211-234, 2007.

Disponível em:<http://www.scielo.br/pdf/er/n30/a14n30.pdf>. Acesso em: 02 jun. 2011.

HORN, M. G. S. O papel do espaço na formação e na transformação do educador infantil. Revista Criança, Brasília, v. 1, n. 38, p. 29-32, jan. 2005. 
HORN, M. G. S. Sabores, cores, sons, aromas: a organização dos espaços na Educação Infantil. Porto Alegre: Artmed, 2004.

KAMII, C. A criança e o número: implicações educacionais da teoria de Piaget para a atuação com escolares de 4 a 6 anos. 11. ed. Campinas/SP: Papirus, 1990.

KAMII, C.; DEVRIES, R. Jogos em grupo na Educação Infantil: implicações da teoria de Piaget. Porto Alegre: Artmed, 2009.

KISHIMOTO, T. (Org.). Jogo, brinquedo, brincadeira e a educação. São Paulo: Cortez, 1996.

KISHIMOTO, T. O brincar e suas teorias. São Paulo: Cengage Learning, 1998.

KISHIMOTO, T. O jogo e a Educação Infantil. São Paulo: Cengage Learning, 1994.

LARROSA, J. Notas sobre a experiência e o sabor de experiência. Revista Brasileira de Educação, n. 19, p. 20-29, jan./fev./mar./abr. 2002. Disponível em:

<http://www.anped.org.br/rbe/rbedigital/RBDE19/RBDE19_04_JORGE_LARROSA_BONDIA.pdf $>$. Acesso em: 5 maio 2009.

LOPES, A. C. T. Educação Infantil e registro de práticas. São Paulo: Cortez, 2009.

LÜDKE, M.; ANDRÉ, M. E. D. A. Pesquisa em educação: abordagens qualitativas. São Paulo: EPU, 1986.

MOURA, M. O. Jogo de boliche. In: MOURA, M. O. (Org.). Controle da variação de quantidades: atividades de ensino. São Paulo: FEUSP, 1996. p. 47-53.

NACARATO, A. M. Narrar a experiência docente... um processo de (auto)formação. In: GRANDO, R. C.; TORICELLI, L.; NACARATO, A. M. (Org.). De professora para professora: conversas sobre iniciAção matemática. São Carlos/SP: Pedro e João Editores, 2008. p. 143-158.

NACARATO, A. M.; LOPES, C. A. E. Práticas de leitura e escrita em educação matemática: tendências e perspectivas a partir do seminário de educação matemática no COLE. In: LOPES, C. A. E.; NACARATO, A. M. (Org.). Educação Matemática, leitura e escrita: armadilhas, utopias e realidade. Campinas/SP: Mercado de Letras, 2009. p. 25-46.

PASSOS, C. L. B. Processos de leitura e de escrita nas aulas de matemática revelados pelos diários reflexivos e relatórios de futuros professores. In: LOPES, C. A. E.; NACARATO, A. (Org.).

Educação matemática, leitura e escrita: armadilhas, utopias e realidades. Campinas/SP: Mercado de Letras, 2009. p. 111-136.

POWELL; A. B.; FRANCISCO, J. M.; MAHER, C. A. Uma abordagem à análise de dados de vídeo para investigar o desenvolvimento de ideias e raciocínios matemáticos de estudantes. Bolema, Rio Claro, SP. v. 17, n. 21, p. 81-140, mai. 2004.

SMOLE, K. C. S. A matemática na Educação Infantil: a teoria das inteligências múltiplas na prática escolar. Porto Alegre: Artmed, 2003.

SOUZA, E. C. Pesquisa Narrativa, (auto)Biografias e História Oral: ensino, pesquisa e formação em Educação Matemática. Ciências Humanas e Sociedade em Revista, Seropédica, v. 32, n. 2, p. 13-27, jul./dez. 2010. 
VAN DE WALLE, J. A. Matemática no ensino fundamental: formação de professores e aplicação em sala de aula. 6. ed. Porto Alegre: Artmed, 2009.

Submetido em Agosto de 2013. Aprovado em Janeiro de 2014. 